\section{Incidental Finding of Idio- pathic Sub-glottic Stenosis in a Patient Managed for Drug Overdose}

\section{Sir,}

The most frequent causes of sub-glottic stenosis are endotracheal intubation and tracheostomy. But, congenital factors and acquired causes i.e., benign and malignant tracheobronchial tumours, neck trauma, chronic inflammatory diseases, such as Wegener's granulomatosis, sarcoidosis, and relapsing polychondritis, can also result in tracheobronchial stenosis. ${ }^{1}$ Anaesthesiologists may come across sub-glottic stenosis in emergent situations; and management of the airway in such conditions, depends on location and severity of tracheal stenosis. Thus, timely diagnosis and early involvement of the multidisciplinary team may lead to safe airway establishment and post-extubation management.

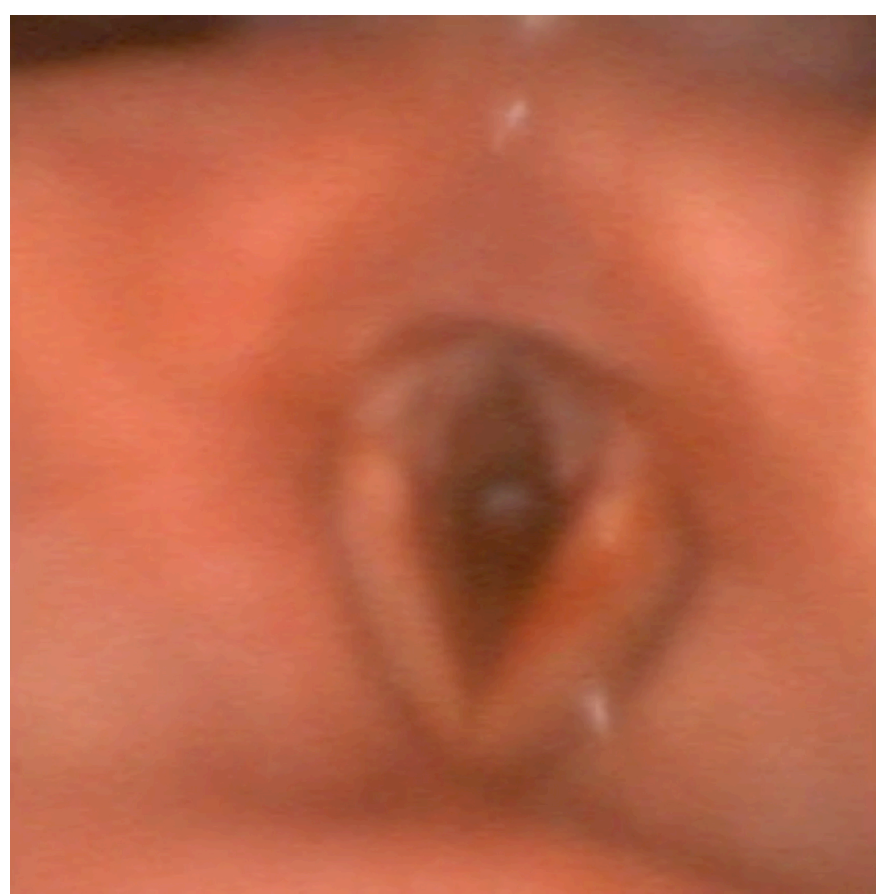

Figure 1: Sub-glottic stenosis on brochoscopy.

Herein, we describe an incidental finding of tracheal stenosis, and its management in a 52-year female with a background history of multiple sclerosis and severe depression as she was brought to the Emergency Department with low Glasgow coma scale (GCS) following drug overdose with baclofen. The first intubation attempt was unsuccessful, but the patient's trachea was intubated in the second attempt by a senior anaesthesiologist using Macintosh laryngoscope and ETT smaller in size $(6.5 \mathrm{~mm}$ I.D.). On improvement in GCS along with stable hemodynamics and ventilatory parameters, she was extubated 36 hours after
ICU admission. But, post-extubation, she developed inspiratory stridor with no evidence of desaturation and hypoventilation. High dose steroids and racemic epinephrine nebulisation were started along with intermittent continuous positive airway pressure (CPAP). On failure of improvement in her symptoms, nasendoscopy (Figure 1) was performed by consultant anaesthetist, which revealed sub-glottic narrowing.

Immediate CT neck was performed that showed sub-glottic stenosis measuring $1.5 \mathrm{~cm}$ in length in the trachea with the narrowest opening of $5 \mathrm{~mm}$ (Figure $2 \mathrm{~A}$ and B). She was intubated again, on the bedside, with micro-laryngeal tube size of 6 $\mathrm{mm}$ I.D, in the presence of ENT team and all emergency drugs and equipment followed by the continuation of high dose steroids and sedation for 48 hours in ICU.

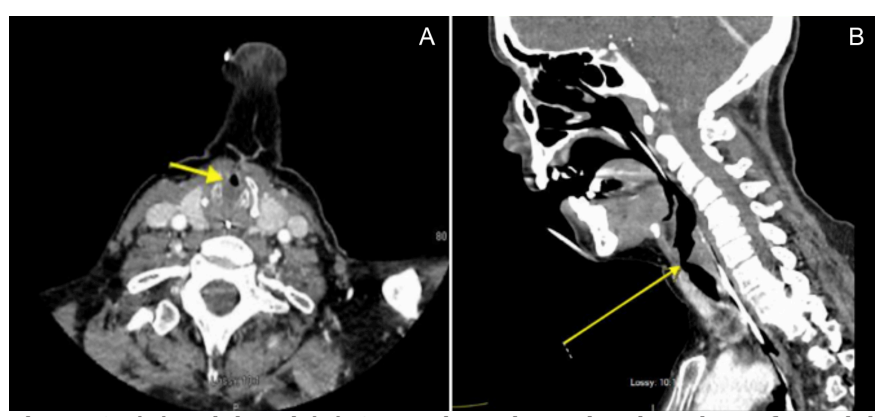

Figure 2: (A) Axial and (B) Coronal sections showing circumferential luminal narrowing of the sub-glottic trachea, with an associated soft-tissuethickening.

She was subsequently extubated after 48 hours after evidence of positive leak test on mechanical ventilation in the presence of consultant anaesthetist and ENT team. There was no new development of stridor or difficulty in breathing, and the patient was subsequently discharged from ICU, with further management in specialised center with ENT expertise. She was managed conservatively with oral steroids and prophylactic antibiotics for few days with future follow-up CT scan after six months or on worsening of symptoms. On latest inquiry, she was symptom-free and will follow the clinic as scheduled.

Tracheal stenosis can have varied presentation. Endoscopy, CT scan and spirometry can be performed as preferred investigations for diagnosis. ${ }^{2}$ We ruled out the congenital and acquired causes of tracheal stenosis before making our final diagnosis. Management of idiopathic tracheal stenosis can be challenging, and it includes mechanical dilation using rigid bronchoscopy or balloon dilation with flexible bronchoscopy, along with more extensive surgeries. ${ }^{3,4}$

A multidisciplinary team approach can be helpful in early diagnosis and timely management.

\section{CONFLICT OF INTEREST:}

The authors declared no conflict of interest.

\section{AUTHORS' CONTRIBUTION:}

SI, SL, EK: Literature search, and initial write-up.

MAM: Literature search, and final write-up. 


\section{REFERENCES}

1. Almanzar A, Danckers M. Laryngotracheal Stenosis. 2020 Nov 24. In: StatPearls. Treasure Island (FL): StatPearls Publishing; 2020 Jan-. PMID: 32119448

2. Filauro M, Mazzola F, Missale F, Canevari FR, Peretti G. Endoscopic preoperative assessment, classification of stenosis, decision-making. Frontiers Pediatrics 2020; 7:532. doi.org/10.3389/fped.2019.00532.

3. Gelbard A, Anderson C, Berry LD, Amin MR, Benninger MS, Blumin JH, et al. Comparative treatment outcomes for patients with idiopathic subglottic stenosis. MJAA Otolaryngology-Head Neck Surgery 2020; 146(1):20-9. doi.org/10.1001/jamaoto.2019.3022

4. Maldonado F, Loiselle A, DePew ZS, Edell ES, Ekbom DC, Malinchoc M, et al. Idiopathic subglottic stenosis:
An evolving therapeutic algorithm. Laryngoscope 2014;

124(2):498-503. doi.org/10.1002/lary.24287.

Saad Ishtiaq, Shankar Lal, Ehtesham Khan and Muhammad Anwar Malik

Department of Anaesthesiology, Our Lady of Lourdes Hospital, Drogheda, Ireland

Correspondence to: Dr. Muhammad Anwar Malik, Department of Anaesthesia, Our Lady of Lourdes Hospital, Drogheda, Ireland

E-mail: manwarmalik@icloud.com

Received: July 07, 2020; Revised: November 16, 2020; Accepted: December 04, 2020

DOI: https://doi.org/10.29271/jcpsp.2021.07.879 